\title{
O Evangelho segundo Jesus Cristo: o trajeto de um herói em busca de sua identidade
}

\author{
Vanessa Neves Riambau Pinheiro*
}

\begin{abstract}
Resumo: O presente trabalho pretende analisar a trajetória do personagem Jesus Cristo, na obra saramaguiana $O$ Evangelho segundo Jesus Cristo. $\mathrm{O}$ herói, durante a trama, entra em conflito de identidade e procura meios para redescobrir-se; nascido em Belém e criado em Nazaré, culpado pelos erros de José e futuramente pelos pecados de Deus, filho de carpinteiro e do Todo-Poderoso, e no entanto aprendiz do sensato Diabo, Jesus procura um meio de se reencontrar enquanto indivíduo. E é esse processo de busca que tencionamos analisar.
\end{abstract}

\begin{abstract}
The present essay is intended to be an analysis of Jesus Christ's journey in Saramago's book called The Gospel According to Jesus Christ. The hero, during the story, starts to find himself in identity doubts and looks for ways to find himself: a hero that was born in Bethlehem and grew up in Nazareth, blamed for Joseph's mistakes and later for God's sins, a carpenter's and God's son and, however, an apprentice of an sensible Devil, Jesus looks for a way to find himself as an individual. This is the search process that we intend to analyze.
\end{abstract}

Keywords: Saramago; journey; hero.

O protagonista da obra que pretendemos analisar não é exatamente um homem moderno, ao menos, cronologicamente falando. Afinal, os estudos recentes acerca da história na qual Saramago se inspirou - a Bíblia Sagrada, mais precisamente os evangelhos de Mateus, Marcos, Lucas e João -, relatam que o nascimento de Jesus teria ocorrido por volta do ano 4a.C. Ainda assim, o caráter da narrativa e do herói se revela extremamente atual e moderno. Basta considerarmos que a narrativa bíblica é recontada por um português ateu e socialista, politicamente engajado e voluntariamente exilado de sua pátria natal. O herói milenar dessa história arquiconhecida aparece com nova roupagem, moralmente conflituoso e eticamente dividido. Um homem sem pátria, que se envergonha dos erros de seu pai terreno e se vê forçado a assumir as culpas de seu pai celeste. Um homem em busca de sua identidade, que não quer conformar-se em ser apenas um bode expiatório da vontade de Deus.

Segundo Zilá Bernd (2003, p. 15), “o conceito de identidade passou a ser largamente estudado desde o momento em que, nas ciências humanas, a idéia de identidade cultural ou coletiva sobressaiu-se à de identidade particular". Ora, apesar de serem esses estudos

\footnotetext{
*Vanessa Neves Riambau Pinheiro é aluna no Programa de Pós-Graduação em Letras da UFRGS.
} 
relativamente novos - anos 60 -, sabemos que, desde sempre, a literatura alimenta a identidade coletiva das nações. Homero criou super-homens gregos; Camões, heróis marítimos invencíveis; e Paulo ${ }^{1}$ organizou e divulgou o que hoje conhecemos por Bíblia Sagrada. Essa consolidou o cristianismo, religião oficial da maioria dos países ocidentais do mundo. E nos apresentou Jesus Cristo, um judeu, como um modelo a ser seguido universalmente. Contraditoriamente, os judeus não acreditam nele.

Sabemos que uma das funções da literatura é a da dessacralização. Saramago propõe a dessacralização do modelo inteiro e perfeito do herói bíblico, dando-lhe dúvidas e hesitações. Saramago realizou o caminho inverso - passou da identidade coletiva à individual. E, por isso mesmo, o herói saramaguiano é fragmentado e imperfeito.

Ao pensarmos na identidade de Jesus Cristo, nos detemos inicialmente no seguinte aspecto: a pátria do herói. Qual é o lugar de origem de seu nascimento? Segundo o evangelho de Mateus, Jesus teria nascido em Belém de Judéia, hipótese essa confirmada pelo narrador de O Evangelho segundo Jesus Cristo. No entanto, Jesus teria vivido praticamente toda sua infância e adolescência na cidade de Nazaré, e até por isso mesmo foi conhecido como Jesus Nazareno. José teria levado sua mulher Maria, grávida de Jesus, a Belém por causa de um recenseamento ordenado pelo rei. Ao descobrirem que Herodes mandaria sacrificar todos os meninos com idade inferior a três anos, José e Maria fugiram, levando o Jesus recém nascido. Belém, então, era para Jesus um lugar desconhecido, pois ele havia saído de lá com poucos dias de vida e seus pais não mais retornaram à cidade durante sua infância, com medo que Herodes os descobrisse.

O herói saramaguiano, no entanto, não se sentia um nazareno, "sonho que estou numa aldeia que não é Nazaré" (SARAMAGO, 2003, p.183). Segundo Ernest Gellner, citado por Stuart Hall em A identidade cultural na pós-modernidade:

\begin{abstract}
A idéia de um homem sem uma nação parece impor uma (grande) tensão à imaginação moderna. Um homem deve ter uma nacionalidade, assim como deve ter um nariz e duas orelhas [...]. Ter uma nação não é um atributo inerente da humanidade, mas aparece, agora, como tal (HALL, 2003, p.49).
\end{abstract}

Jesus aparece, então, como um homem ignorante de suas próprias origens. Com a morte do pai e a descoberta da omissão dele no caso dos meninos mortos, "o meu pai matou os meninos de Belém [...], sabendo que os meninos iam ser mortos não avisou os pais deles" (SARAMAGO, 2003, p.187), Jesus sente que precisa ir em busca de sua própria história, redescobrir um lar, pois já não reconhece mais o seu. A revelação da culpa de José surge

\footnotetext{
${ }^{1}$ Segundo as Escrituras Sagradas, Paulo de Tarso - a quem Deus teria trocado o nome de Saulo por Paulo - foi o primeiro homem conhecido por viajar propagando as idéias de Jesus.
} 
como se fosse um véu que lhe tiraram dos olhos e junto a paz da ignorância. "Dor e consciência encontram-se, então, numa relação diretamente proporcional: 'a nossa existência é tanto mais feliz quanto menos a sentirmos', e 'quanto mais elevado o grau de consciência, maior a dor" (SCHOPENHAUER apud BARRENTO, 2001, p.73).

A partir dessa conscientização, a relação harmoniosa de Jesus com a família se rompe: ao desconhecer a casa em que sempre morou como seu lar e seus familiares como seus, Jesus decide partir:

Disse Maria, Vamos para casa, não temos mais nada a dizer aqui, e o filho respondeu-lhe, Vai tu, eu fico. Parecia que se perdera o rasto de ovelha ou pastor, o deserto era de facto um deserto, e até as casas alem, soltas ao acaso pela encosta abaixo, pareciam grandes pedras talhadas, de um estaleiro abandonado, que aos poucos se fossem enterrando no chão [...]. Passados dois dias, Jesus foi-se embora de casa. (SARAMAGO, 2003, p.188-191).

A peregrinação iniciada por Jesus contribui fortemente em seu processo identitário. Ao vasculhar locais e consultar pessoas que possam lhe ajudar a reorganizar seus pensamentos, Jesus começa a se desvelar. "Uma identidade nunca é dada, recebida ou atingida; só permanece o processo interminável, indefinidamente fantasmático da identificação" (DERRIDA apud BERND, 2003, p.21).

Jesus foi a Belém procurar vestígios de seu nascimento e da matança que atingiu vinte e cinco meninos há catorze anos, e lá encontra uma senhora, criada dos donos do estábulo em que Jesus nasceu, que foi sua parteira. Essa mulher o leva à cova onde ele viveu seus primeiros dias de vida. A partir de então, Jesus, outrora tão seguro de sua fé na justiça e bondade de Deus, começa a se questionar. "Pode bem pouco, afinal, a mão de Deus, se não chega a interpor-se entre o cutelo e o sentenciado" (SARAMAGO, 2003, p.219).

Ainda inquieto sobre sua origem, peregrina por vários lugares, e vai a um Templo, onde encontra um escriba que é tido como sábio. "O discurso de Cristo é um discurso angustiado, cheio de perguntas, ele é um argüidor desesperado que encurrala seus interlocutores, procurando a verdade de sua vida" (cf. FERRAZ, 1998, p.94). Desse sábio ele obtém uma resposta, "a culpa é um lobo que come o filho depois de ter devorado o pai" (SARAMAGO, 2003, p.213), mas essa não o satisfaz plenamente. "É o início da consciência de que está num labirinto complicado do qual não sairá com vida" (cf. FERRAZ,1998 p.97). É então que Jesus vai viver pastoreando ovelhas com o Pastor, um homem que o conhece "conheço-te desde sempre, como vês" (SARAMAGO, 2003, p.226), e por quem ele sente um inexplicável fascínio.

Sabemos que esse Pastor, com quem Jesus vive durante quatro anos, é o Diabo. Esse homem o instrui, desperta seu espírito crítico e contestador. Durante os anos em que Jesus 
vive com o Pastor, ele aprende mais sobre sua própria natureza: "Deus não poderá rejeitar como obra não sua o que levas entre as pernas" (SARAMAGO, 2003, p.237); sobre a ambigüidade de Deus: "Não é lícito fornicar-vos [as ovelhas], Deus não o permite, podeis estar tranqüilas, mas tosquiar-vos, sim, maltratar-vos, sim, matar-vos, sim, e comer-vos, pois para isso vos criou a sua lei e vos mantém a sua providência” (SARAMAGO, 2003, p.238), e até mesmo sobre a impiedade do Senhor: "Ainda bem que [Deus] não dorme, assim evita os pesadelos do remorso" (SARAMAGO, 2003, p.233). É nesse ínterim que Cristo, já desconfiado da real identidade do Pastor, tem seu primeiro encontro com Deus. Deus lhe aparece como um velho irritado: "cala-te, não perguntes mais" (SARAMAGO, 2003, p.263); impaciente: "que enfadonho que és, homem, que temos mais agora" (SARAMAGO, 2003, p.264); cruel: "estás a chorar, perguntou Deus [...], a ovelha não soltou um som, apenas se ouviu, Aaaah, era Deus suspirando de satisfação”(SARAMAGO, 2003, p.264); e autoritário: “vá, despacha-te, tenho mais o que fazer" (SARAMAGO, 2003, p.264). Deus obriga Jesus a sacrificar a única ovelha que Jesus havia prometido resguardar, e faz isso para mostrar que, assim como a inocente ovelha fora vítima de uma morte vil, também ele, Cristo, será uma cobaia nas mãos de Deus. Mais uma vez percebemos aqui uma ironia: quem tenta Cristo no deserto é Deus, e não o Diabo, como ocorre nos escritos da Bíblia Sagrada.

Antes de encontrar Deus, Jesus tinha um problema: tinha vergonha do erro de seu pai José e necessidade de se redescobrir. Depois desse encontro, o problema se agravou: Jesus sabe-se filho de Deus. E identifica-se com o Diabo. Percebemos, dessa forma, a fina ironia saramaguiana: se Jesus saiu de casa em busca de um modelo de pai novo para amar e respeitar, o encontrado não foi Deus, e sim, o Diabo. O Pastor foi quem o acolheu, quem lhe ensinou o ofício de pastorear ovelhas - Jesus não chegou a aprender o ofício de carpintaria com José-, e quem o aconselhou a repensar sua fé. O modelo paterno, que substituiu o pai morto e pecador de Jesus, foi o Diabo. Todas as diferenças de pensamento que o Pastor e Jesus tinham, apenas contribuíram para fortalecer essa identificação mútua entre os dois. Cito Zilá Bernd:

A identidade é um conceito que não pode afastar-se do de alteridade: a identidade que nega o outro, permanece no mesmo. Excluir o outro leva à visão especular que é redutora: é impossível conceber o ser fora das relações que o ligam com o outro [...]. Trata-se, pois, de apreender a identidade como uma entidade que se constrói simbolicamente no próprio processo de sua determinação. A consciência de si toma sua forma na tensão entre o olhar sobre si próprio - visão do espelho, incompleta - e o olhar do outro (BERND, 2003, p.17).

Tudo o que Jesus não era - herético, sensual, questionador da fé - aparece na figura do Pastor, causando um retumbar em sua alma. Apesar das duras palavras do Diabo a Jesus, "não aprendeste nada, vai” (SARAMAGO, 2003, p.265), sabemos que o herói é outro ao deixar o 
rebanho de ovelhas que ajudava a pastorear. Ou melhor: Jesus não é outro, apenas aprendeu, com o convívio com um diferente de si, a se conhecer melhor. Uma importante etapa no processo de individuação do herói. "Também se aprende com o Diabo" (SARAMAGO, 2003, p.254).

Sabemos, no entanto, que, na obra de Saramago, Deus e o Diabo aparecem como complementares, o que evidencia a complexidade de todo ser humano, que tem ambos dentro de si. "Este Bem que eu sou não existiria sem este Mal que tu és" (SARAMAGO, 2003, p.392).

Segundo Georg Lukács (2000), em A teoria do romance, há uma espécie de herói intermediário entre o idealismo abstrato de Dom Quixote, personagem de Miguel de Cervantes, e o romantismo ilusório de Werther, célebre herói de Goethe.

Seu tema é a reconciliação do indivíduo problemático, guiado pelo ideal vivenciado, com a realidade social concreta. Essa reconciliação não pode nem deve ser uma acomodação existente desde o início [...]. Tipo humano e estrutura da ação, portanto, são condicionados aqui pela necessidade formal de que a reconciliação entre interioridade e mundo seja problemática mas possível (LUKÁCS, 2000, p.138).

Essa espécie de herói é capaz de equilibrar sua forte interioridade com sua capacidade de ação. E ele precisa obter, ao longo da narrativa, algum aprendizado. Esse aprendizado é necessário para que o herói encontre uma reconciliação entre sua interioridade, que o confunde, e o mundo exterior, o qual ignora.

Percebemos que o motivo da busca de suas origens, das reais condições de seu nascimento, da
paternidade legítima ou não de José, se faz presente na trajetória do personagem Cristo [...]. O
filho de José parte da casa paterna muito cedo, e vai em busca de sua verdade, peregrinando
por Jerusalém, Belém da Judéia, pelo deserto, por Magdala, pelo mar da Galiléia e retorna com
dezoito anos, já homem, à sua pátria, em Nazaré, plenamente ciente de seu destino (FERRAZ,
1998, p.97).

A viagem é um dos caminhos mais freqüentes nesse processo. Podemos considerar Jesus um desses heróis que, perturbado a partir da descoberta do erro do pai, parte para tentar redescobrir-se e reconciliar-se consigo mesmo e com o mundo. O mundo exterior, para Cristo, era a casa em Nazaré onde vivia com sua família. Depois que decidiu partir, Jesus viajou por diversos lugares, conheceu o lugar em que nasceu, encontrou-se com Deus e envolveu-se com Maria de Magdala, a prostituta que lhe acompanhará até os últimos dias de sua vida. Maria de Magdala aparece na vida de Jesus no momento em que ele mais precisava. Ferido, encontra cuidado e carinho nos braços da cortesã. Quando nem a mãe mais lhe acredita, ela o ampara e confia nele. $\mathrm{O}$ filho de Deus, virgem e incauto, encontra o verdadeiro amor em uma prostituta. É mais uma vez a alteridade a favor do redescobrimento íntimo do herói. 
A etapa última do desvelar-se do herói se dá no seu encontro mais importante com Deus e o Diabo, no barco, onde ele ouve textualmente as intenções funestas de seu pai celestial. "E qual foi o papel que me destinaste no teu plano, O de mártir, meu filho, o de vítima, que é o que de melhor há para fazer espalhar uma crença e afervorar uma fé" (SARAMAGO, 2003, p.370). Podemos, então, perceber a maturidade de Jesus. O que, em tempos idos, seria um privilégio ao religioso judeu, agora se configura um descaminho. "Rompo o contrato, desligo-me de ti, quero viver como um homem qualquer" (SARAMAGO, 2003, p.371). E, apesar da vergonha que um dia o fez sair de casa, vergonha do pai infame e omisso, que contribuiu com seu silêncio para o assassinato dos vinte e cinco meninos de Belém, Jesus sente imensa vontade de voltar a crer-se filho de José. "Se ainda posso escolher um pai, escolho-o a ele, mesmo tendo sido ele, como foi, infame uma hora da sua vida" (SARAMAGO, 2003, p.371). Jesus, então, descobre que será o ícone de uma nova religião, o cristianismo, que dominará o mundo ocidental. "Haverá uma Igreja, que, como sabes, significa assembléia, uma sociedade religiosa que tu fundarás, ou em teu nome será fundada" (SARAMAGO, 2003, p.379).

A grande verdade é que Cristo não quer a missão que lhe foi confiada, não quer a salvação eterna para os homens, deseja apenas que eles vivam essa vida, envelheçam e morram em paz. $\mathrm{E}$, sob esse particular, o narrador procura mostrar o lado humano dessa personagem que os evangelhos bíblicos minimizam, em favor de seus atributos divinos (FERRAZ, 1998, p.101).

Ao conformar-se com sua imposta morte, "faça-se em mim segundo a tua vontade" (SARAMAGO, 2003, p.377), Jesus não assume um comportamento passivo. Ele sabe, desde que descobriu o crime de José, que o conhecimento pode trazer dor. Mas sua maturidade o leva para este caminho novamente, e Jesus exige saber de Deus o que acontecerá às pessoas que o seguirem:

O que eu quero que me digas é como viverão os homens depois de mim vierem, Refere-te aos que te seguirem, Sim, se serão mais felizes, Mais felizes, o que se chama felizes, não direi, mas terão a esperança de viverem eternamente comigo, Nada mais, Parece-te pouco [...]. Insiste em querer sabê-lo, Insisto, Pois bem, edificar-se-á a assembléia de que te falei, mas os caboucos dela, para ficarem bem firmes, haverão de ser cavados na carne, e os seus alicerces compostos de um cimento de renúncias, lágrimas, dores, torturas, de todas as mortes imagináveis, hoje e outras que só no futuro serão conhecidas, Finalmente, estás a ser claro e directo (SARAMAGO, 2003, p.379-380).

Jesus, que já carrega a culpa de seu pai terreno, agora se vê imerso nas culpas de seu pai celestial. "Pois eu, se já levo esta carga de ter de morrer por ti, também posso agüentar os remorsos que deveriam ser teus" (SARAMAGO, 2003, p.390).

Apesar da tentativa do Diabo de poupar Cristo, ao propor uma reconciliação com Deus: "Não me aceitas, não me perdoas, Não te aceito, não te perdôo, quero-te como és, e, se possível, ainda pior do que és agora" (SARAMAGO, 2003 p.392), o destino foi selado: Cristo 
irá morrer na cruz como mártir. Jesus, no final de seu processo identitário, reconhece-se bem agora e tem horror ao que vê:

Eu sou o pastor que, com o mesmo cajado, leva ao sacrifício os inocentes e os culpados, os salvos e os perdidos, os nascidos e os por nascer, quem me libertará deste remorso, a mim que me vejo hoje, como meu pai naquele tempo, mas ele é por vinte vidas que responde, e eu por vinte milhões (SARAMAGO, 2003, p.404).

Ao final de sua trajetória de aprendizagem, Jesus aparece lúcido e consciente, mas nem por isso menos angustiado. A roupagem humanista que Saramago lhe dá impossibilita a tranqüilidade. Saramago "reconstitui e resgata um Cristo mais humano do que divino, muito mais preocupado com os anseios da alma humana do que com os desejos absurdos de Deus" (cf. FERRAZ, 1998, p.93). Dessa forma, o herói se vê imerso em um conflito ético/moral insolúvel. Não existe opção possível ao escolhido de Deus, pois, como bem frisou Maria Madalena, "não sei nada de Deus, a não ser que tão assustadoras devem ser as suas preferências como os seus desprezos" (SARAMAGO, 2003, p.309). Jesus é herdeiro do destino de seu pai José, tanto o de morrer crucificado quanto o de ser responsável indireto por crimes de morte. Sua jornada o humanizou, o fez aprender, o tornou sábio e maduro. Mas não o impediu de ser um cruel joguete nas mãos de Deus. Não havia opção. E saber disso foi a única forma que Cristo encontrou para reconciliar-se consigo e com o mundo.

\section{Referências}

BARRENTO, João. A espiral vertiginosa. Lisboa: Cotovia, 2001.

BERND, Zilá. Literatura e identidade nacional. Porto Alegre: UFRGS, 2003.

FERRAZ, Salma. O quinto evangelista: o (des) evangelho segundo José Saramago. Brasília: UNB, 1998.

HALL, Stuart. A identidade cultural na pós-modernidade. Rio de Janeiro: DP\&A, 2003.

LUKÁCS, Georg. A teoria do romance. São Paulo: Editora 34, 2000.

SARAMAGO, José. O Evangelho segundo Jesus Cristo. São Paulo: Companhia das Letras, 2003. 